\title{
THE CONSTRUCT VALIDATION OF AN INSTRUMENT DESIGNED TO ASSESS ORGANISATIONAL SOCIALISATION
}

\author{
MICHELLE MADURAI \\ CHANTAL OLCKERS \\ MICHIEL BUYS \\ Department of Human Resources Management \\ University of Pretoria \\ South Africa \\ Correspondence to: Chantal Olckers \\ Email: chantal.olckers@up.ac.za
}

\begin{abstract}
The aim of this study was to establish the construct validity of an instrument for assessing organisational socialisation. A purposive sample of 170 respondents completed the socialisation instrument. Scale reliabilities and a confirmatory factor analysis confirmed six constructs (History, Language, Politics, People, Organisational Goals and Values, and Performance Proficiency) as measures of this domain. The significance of the findings of this study is that from a South African perspective, the socialisation instrument can be useful in measuring organisational socialisation. This instrument can also be valuable in assessing the effectiveness of the socialisation tactics used by organisations.
\end{abstract}

Keywords: tactics, reliabilities, relationships, workplace, culture

Organisational socialisation is an integral component of the employer-employee relationship. It focuses on the process that newcomers go through when they join a new organisation or change jobs or roles. When organisational socialisation involves the experience of joining a new organisation, it requires that an employee identify with the organisation, take on its values and culture and become a fully functioning member of the organisation. When it involves a change in job or role, the employee has to learn the tasks of the job or role successfully and become an accepted, functioning team member.

Organisational socialisation has been defined from various perspectives. It has been regarded as a continuous process by which a newcomer adjusts to a new organisational setting, adapts to the organisational culture, becomes functional in the new role or job he or she is employed in and learns the ropes of the new position as structured by others within the new setting (Chao, O'Leary-Kelley, Wolf, Klein \& Gardner, 1994; Chow, 2002; Klein \& Weaver, 2000; Manning, 1977; Porter, Lawler \& Hackman, 1975; Robbins, 1998; Van Maanen, 1978). For the purpose of this study, the definition of Chao et al. (1994), which states that organisational socialisation is the primary process through which people should adapt to new jobs and organisational roles, will be applied.

Organisational socialisation as a subject has been extensively researched. Previous research has focused on various areas of this dimension. These include the process of, the general characteristics of, the socialisation tactics employed in and the content of organisational socialisation.

\section{Process of organisational socialisation}

Research on the process of organisational socialisation has focused on the stages through which newcomers pass when they join a new organisational setting. Most of this research is based on stage model theory (Chao et al., 1994; Chow, 2002; Feldman, 1976; Feldman, 1981; Klein \& Weaver, 2000; Louis, 1980; Ostroff \& Kozlowski, 1992). According to the stage model theory, at each stage, newcomers engage in a different set of activities in an attempt to make sense of the new environment they find themselves in (Chow, 2002; Feldman, 1976; Lewis, Goodman \& Fandt, 1998; Louis, 1980; Porter et al., 1975).

The first stage has been referred to as the anticipatory or prearrival stage (Feldman, 1976; Feldman, 1981; Porter et al., 1975; Robbins, 1998). This stage is concerned with all the learning that takes place prior to newcomers' joining the new organisational setting. It is in the next stage (known as the accommodation or encounter stage) that the preconceived ideas newcomers have of the new setting are tested against reality (Feldman, 1976; Feldman, 1981; Porter et al., 1975; Robbins, 1998). This testing of newcomers' anticipations against reality could result in 'reality shock' if there is a significant difference between their anticipations and the reality of the organisational setting (Dessler, 1984; Louis, 1980). The third stage is known by several names, such as role management, metamorphosis, settling in or change and acquisition (Feldman, 1976; Nel, Gerber, Van Dyk, Haasbroek, Schulz, Sono \& Werner, 2001; Porter et al., 1975; Robbins, 1998). As a result of the pressure newcomers feel from the previous stage, they may change some of their modes of behaviour as well as acquire new modes of behaviour, both of which are crucial for them to adapt successfully to the organisation. When they reach this stage, they become fully accepted members (Chow, 2002; Louis, 1980; Porter et al., 1975).

One limitation of the research on stage models of organisational socialisation is that so far it has failed to describe how the changes that occur during the process of organisational socialisation actually take place (Chow, 2002; Louis, 1980). Initial research focused on organisational socialisation as a process that new employees go through. However, later research has shown that newcomers in any new organisational setting work through a socialisation process (Chao et al., 1994; Louis, 1980). Hence organisational socialisation is a continuous process that often occurs and continues throughout an individual's career (Ivancevich \& Matteson, 1990).

\section{Characteristics of the process}

Joining a new organisational setting is often a stressful and unnerving experience that induces high levels of frustration, insecurity, anxiety and discomfort, due to the unfamiliarity of the new environment and work group (Louis, 1980; Nel et al., 2001; Porter et al., 1975). These emotions stem from newcomers' concern about whether or not they will meet the requirements of the position and whether or not they will be accepted by members of the new work group (Jones, 1983; Louis, 1980). Louis (1980) developed a model of how newcomers make sense of and cope with the new organisational setting, focusing on three features of the experience of entering a new setting: The newcomer experiences change in the differences between the old and the new setting, the contrast between the features of 
the new setting and what the newcomer was used to makes it difficult for the newcomer to make sense of the new situation and the newcomer may experience surprise at finding that his or her expectations of the new setting are not met.

\section{Socialisation tactics}

Many factors influence the socialisation of newcomers. These include the working routines of the new organisational setting, the first supervisor whom newcomers are exposed to and their daily interaction with organisational members (Louis, 1980; Ostroff \& Kozlowski, 1992; Schein, 1992).

Both organisations and newcomers use many socialisation tactics to enable the process of organisational socialisation Newcomers require coaching, guidance, support, feedback and opportunities to increase their levels of understanding and to be able to function in the new organisational setting (Lewis et al., 1998). Organisations use socialisation tactics to influence the learning process that newcomers experience by shaping the information they receive in a particular manner (Jones, 1986).

In his much-cited research on "people processing" strategies, Van Maanen (1978) describes various types of socialisation strategy. First, formal socialisation strategies: This refers to the degree to which the setting in which socialisation takes place is segregated from the ongoing work context. Second, individual socialisation strategies: This is the degree to which individuals are socialised singly or collectively. Third, sequential socialisation strategies: This refers to transitional processes marked by a series of discrete and identifiable stages through which an individual must pass in order to achieve a defined role and status within the organisation. Fourth, fixed socialisation strategies: This provides a recruit with a precise knowledge of the time it will take him or her to complete a given step. Fifth, tournament socialisation strategies: This is the practice of separating selected clusters of recruits into different socialisation programmes. Sixth, serial socialisation strategies: This is the process whereby experienced members groom newcomers for the assumed roles in the organisation and is perhaps the best guarantee that an organisation will not change over long periods of time. Last, investiture socialisation strategies: This is the degree to which a socialisation process is set up either to confirm or to dismantle the incoming identity of a newcomer. All of these strategies have their advantages as well as their disadvantages, and they are selected based on their relevance to the organisational setting.

Many researchers have studied organisational socialisation tactics from an interactionist perspective. Their view is that when an organisation implements formal socialisation tactics such as mentorship, orientation programmes and on-thejob training, the newcomer in turn proactively uses certain informal tactics such as relationship building, informal mentor relationships, positively framing the new role, observation and involvement in work-related activities to acquire information and support from organisational members (Griffin, Colella \& Goparaju, 2000; Jones, 1983; Jones, 1986; Reichers, 1987; Wanous, Reichers \& Malik, 1984).

\section{Content of organisational socialisation}

The content of organisational socialisation has been researched in terms of what newcomers actually learn during this process, what enables them to fit in and be accepted and whether they have mastered the job they have been employed to do (Chao et al., 1994; Chow, 2002; Feldman, 1981; Klein \& Weaver, 2000; Louis, 1980). It includes information that newcomers need to acquire about organisational issues such as policies, procedures, rules, history and politics, information about how to perform the work tasks of the new role and information about the expectations and responsibilities of the new role (Morrison, 2002).
In their socialisation instrument, Chao et al. (1994) identified six content areas of organisational socialisation. These are History, Language, Politics, People, Organisational Goals and Values, and Performance Proficiency.

\section{History}

There are certain customs, myths, stories, traditions and rituals that are unique to the organisational setting and form part of its identity. The history of an organisation is reinforced and sustained through these customs, myths, rituals, traditions and stories told about and by organisational members. It is influenced by the organisation's culture and is used to transmit knowledge about the organisation's culture and to sustain it (Chao et al., 1994; Ritti, 1994). The stories told are narrative events concerning the organisation's founder, rule-breaking incidents and the consequences thereof, success stories, past restructuring exercises of the organisation and the consequences of mistakes that legitimise current practices in the organisation (Robbins, 1998). These stories convey messages to newcomers and existing members about what behaviour is rewarded, punished, supported and expected (Schneider, 1987).

\section{Language}

Every organisational setting has a unique language that organisational members use and that enables them to understand their roles and how their organisation functions (Chao et al., 1994). This language is made up of technical terms, jargon, acronyms, specific phrases and buzzwords. For effective communication to take place amongst organisational members, a "common language and common conceptual categories" are essential (Schein, 1992). Understanding the language informs use of the language, which is crucial for newcomers to function in the new setting. Manning (1977) believes that a set of rules that governs the use of terms and phrases exists in the organisation. Hence newcomers not only need to learn the language but also need to learn the governing rules in order to ensure that they use the language appropriately in performing their duties.

Politics

Organisational politics are an integral part of any organisation. They affect what happens in the organisation and who makes it happen. Pfeffer (1981) defines organisational politics as "those activities taken within organisations to acquire, develop and use power". It is crucial to understand the power structures and formal and informal working relationships of the new organisational setting and to learn what norms sanction the power structures in the organisational setting (Chao et al., 1994; Pfeffer, 1981). Knowing who has influence and knowledge enables newcomers to learn and adjust to the new setting more effectively. When they achieve a heightened awareness of the politics in the organisation, newcomers are equipped for and more confident in approaching intergroup conflicts and attempting to resolve them (Feldman, 1981).

\section{People}

Establishing successful relationships with members of the new organisational setting is pertinent to newcomers' learning about how the workgroup functions and what is considered appropriate behaviour (Chao et al., 1994). For effective interaction to take place, they need to establish functioning relationships with insiders to observe and learn about the new setting, to fit in and to be accepted. Through interaction, they adopt the attitudes of the new work group and become able to soundboard with the members in terms of their interpretations of their experiences in the new setting (Louis, 1980; Reichers, 1987; Ritti, 1994; Schneider \& Reichers, 1983; Van Maanen, 1978). Morrison (2002) states that newcomers establish "friendship or expressive" networks that provide support, a sense of belonging and identity. Personality traits, the nature of the work, similar personal interests, the structure of the organisational setting 
and group dynamics play a pivotal role in the newcomer's being accepted by the work group (Chao et al., 1994; Jones, 1983; Wanous et al., 1984).

\section{Organisational Goals and Values}

Organisational goals and values include both formal goals and values and informal, implicit goals and values that exist and are supported by the organisation's members, particularly those in powerful positions (Chao et al., 1994; Pfeffer, 1981; Schein, 1992). Understanding the unspoken norms, informal networks and rules that maintain the integrity of the organisation enables newcomers to learn the new work group's norms and values and to make sense of organisational situations (Chatman, 1991; Feldman 1981; Schein, 1968). The organisation's values are guided and moulded by the organisational culture and they have a powerful influence on the newcomer's behaviour (Newstrom \& Davis, 1993). They convey "how things get done and what matters" in the new setting and what is expected from the newcomer to avoid expulsion (Louis, 1980). As the organisation attempts to socialise the newcomer successfully, the newcomer in turn attempts to influence the organisation's value system and way of doing things (Griffin et al., 2000; Porter et al., 1975).

\section{Performance Proficiency}

Newcomers need to learn about the new job, including understanding where the job fits into the organisational structure, what it entails and what skills and knowledge are required to perform effectively (Chao et al., 1994; Louis, 1980). They do this by getting involved in work-related activities that provide opportunities for them to learn about the job and organisation (Bauer \& Green, 1994). Newcomers acquire this learning through both interpersonal and non-interpersonal sources. Interpersonal sources include the supervisor, group members and mentors. Non-interpersonal sources include written organisational material such as policies, systems and procedures, and observations of behaviour of other members (Ostroff \& Kozlowski, 1992). In their research on on-the-job training, Gomersall and Myers (1966) found that the anxiety and frustration newcomers experience in the new setting interfere with their learning. However, as they become more self-confident and begin to master the tasks of the new role, they begin to achieve and maintain high performance (Feldman, 1981).

The purpose of the study is to determine whether the socialisation instrument designed by Chao et al. (1994) measures the dimension of organisational socialisation when it is applied within the South African context. The study is concerned with whether this instrument measures what it purports to measure.

The content areas discussed are by no means to be seen as exhaustive (Chao et al., 1994). Given that they comprise the instrument that is validated in this study, they have been elaborated upon below.

\section{METHOD}

\section{Participants}

A purposive sample of 170 respondents completed the socialisation instrument. The biographical information on the respondents is set out in Table 1. The sample consisted of approximately $54 \%$ black, 9\% coloured, $17 \%$ Indian and $20 \%$ white respondents. Of the respondents, $36 \%$ were male and $64 \%$ were female. Approximately $24 \%$ of the respondents indicated that English was their first language and $24 \%$ indicated Afrikaans as their first language. Of the respondents, 53\% indicated an African language as their first language. In terms of age, approximately $88 \%$ of the respondents were between 20
TABLE 1

Respondents' biographical details

\begin{tabular}{lrrr}
\hline & Frequency & Percentage & Cumulative \% \\
\hline GENDER & & & \\
\hline Male & 61 & 35.9 & 35.9 \\
Female & 109 & 64.1 & 100 \\
Total & 170 & 100 & \\
AGE & & & \\
\hline $25-30$ & 149 & 87.6 & 87.6 \\
$31-35$ & 10 & 5.9 & 93.5 \\
$36-40$ & 7 & 4.1 & 97.6 \\
$41-45$ & 2 & 1.2 & 98.8 \\
$46-50$ & 2 & 1.2 & 100 \\
Total & 170 & 100 & \\
RACE & & & \\
\hline Black & & 54.1 & \\
Coloured & 92 & 9.4 & 100 \\
Indian & 16 & 20 & \\
White & 28 & 100 & \\
Total & 34 & & \\
\end{tabular}

HOME LANGUAGE

\begin{tabular}{|c|c|c|c|}
\hline English & 40 & 23.5 & 23.5 \\
\hline Afrikaans & 40 & 23.5 & 47.1 \\
\hline North Sotho & 18 & 10.6 & 57.6 \\
\hline Setswana & 26 & 15.3 & 72.9 \\
\hline isiXhosa & 3 & 1.8 & 74.7 \\
\hline isizulu & 19 & 11.2 & 85.9 \\
\hline SeSotho & 13 & 7.6 & 93.5 \\
\hline xiTsonga & 3 & 1.8 & 95.3 \\
\hline isiNdebele & 4 & 2.4 & 97.6 \\
\hline tshiVenda & 2 & 1.2 & 98.8 \\
\hline seSwatii & 2 & 1.2 & 100 \\
\hline Total & 170 & 100.1 & \\
\hline \multicolumn{4}{|c|}{ QUALIFICATION } \\
\hline Grade 12 & 73 & 42.9 & 42.9 \\
\hline Certificate & 38 & 22.4 & 65.3 \\
\hline Diploma & 33 & 19.4 & 84.7 \\
\hline Degree & 14 & 8.2 & 95.9 \\
\hline Postgraduate & 12 & 7.1 & 97.6 \\
\hline Total & 170 & 100 & 100 \\
\hline \multicolumn{4}{|c|}{ NATURE OF POSITION } \\
\hline Clerical & 110 & 64.7 & 65.1 \\
\hline Consultant & 28 & 16.5 & 81.7 \\
\hline Specialist & 24 & 14.1 & 95.9 \\
\hline Supervisory & 3 & 1.8 & 97.6 \\
\hline Managerial & 4 & 2.4 & 100 \\
\hline Subtotal & 169 & 99.4 & \\
\hline Unknown & 1 & 0.6 & \\
\hline Total & 170 & 100 & \\
\hline
\end{tabular}

and 30 years old. The category 31 to 40 years old was represented by $10 \%$ of the respondents. Only $2 \%$ of the respondents were between 41 and 50 years old. Of the respondents, $43 \%$ had matriculated, while $57 \%$ had obtained a qualification from a tertiary institution. Regarding the nature of the positions that the respondents held, $65 \%$ were in clerical positions, $31 \%$ were consultants or specialists, $2 \%$ were supervisors and $2 \%$ were in managerial positions.

\section{Measuring instrument}

The measurement instrument used was the socialisation questionnaire developed by Chao et al. (1994). The instrument consists of six content areas of organisational socialisation: History, Language, Politics, People, Organisational Goals and Values, and Performance Proficiency. It consists of 40 items that tap into these six areas. The items are anchored in the form of a five-point Likert scale. Table 2 indicates the items per factor for the instrument. 
TABLE 2

Items per factor for the socialisation instrument

\begin{tabular}{|c|c|c|c|c|c|c|}
\hline Factor & $\begin{array}{l}\text { History } \\
\text { (5 items) }\end{array}$ & $\begin{array}{l}\text { Language } \\
\text { (5 items) }\end{array}$ & $\begin{array}{l}\text { Politics } \\
\text { (6 items) }\end{array}$ & $\begin{array}{l}\text { People } \\
\text { (6 items) }\end{array}$ & $\begin{array}{l}\text { Organisational } \\
\text { goals \& values } \\
\text { (7 items) }\end{array}$ & $\begin{array}{l}\text { Performance } \\
\text { proficiency } \\
\text { (5 items) }\end{array}$ \\
\hline \multirow{7}{*}{ VARIABLES } & V8R & $\mathrm{V} 12 \mathrm{R}$ & V7 & $\mathrm{V} 10 \mathrm{R}$ & V9 & V11R \\
\hline & V15R & V18R & V13 & V16R & V17 & V14 \\
\hline & V20 & V21R & V29R & V19 & V22 & V25 \\
\hline & V27 & V24 & V32R & V33R & V23R & V28R \\
\hline & V35 & V36 & V34 & V37 & V26 & V30 \\
\hline & & & V38 & V39 & V31 & \\
\hline & & & & & V40 & \\
\hline
\end{tabular}

The reliabilities of the six constructs were determined using Cronbach's alpha coefficient (Chao et al., 1994). In their study, Chao et al. (1994) reported acceptable reliability coefficients higher than or equal to 0.78 . Klein and Weaver (2000) used the same socialisation instrument in their study and their research yielded high reliability coefficients ranging between 0.63 and 0.86 for the six constructs. However, according to Storm and Roodt (2002) the factor structure of the original questionnaire did not hold for the South African context. Only two factors, namely organisational socialisation with a reliability of 0,918 and organisational commitment with a reliability of 0,775 , emerged.

\section{Data analysis}

Descriptive statistics in respect of the socialisation instrument were computed for the respondents. These statistics included a descriptive analysis of the biographical data as well as of the content items of the instrument. In addition, the reliability of the instrument and the reliabilities of each of the six constructs measured were determined. The Statistical Package for the Social Sciences (SPSS) for Windows program was used to do the necessary analysis. In order for the reliability coefficients to be a true reflection of what was measured, a number of items that were originally negatively stated had to be reversed.

After considering the arguments of Harvey, Billings and Nilan (1985) on the difference between confirmatory factor analysis (CFA) and exploratory factor analysis (EFA), the authors decided to perform only a CFA for the purposes of this study. According to Harvey et al. (1985) the use of CFA allows researchers to formulate and directly test competing hypotheses regarding the underlying factor structure. EFA on the other hand has the following limitations: If the predicted factor solution is not found, two interpretations are possible: First, there are true differences between the actual and predicted factor structure, or, second, the EFA was unable to uncover the hypothesised structure. The most troublesome difficulty with EFA is selecting the appropriate underlying dimensionality.

CFA has strong links with structural equation modelling (SEM). As a confirmatory approach, a model is postulated, based on theory and empirical evidence from previous research. Then the model is tested using SEM goodness-of-fit tests to determine whether the pattern of variances and covariances in the data is consistent with the postulated theoretical model (Garson, 2005). The SEM process was used to conduct the CFA because it focuses on validating the measurement model by obtaining estimates of the parameters of the model and by assessing whether the model itself provides a good fit to the data (Garson, 2005).

The first step of the research process was to define the theoretical factor model. This involved selecting the number of factors to be used and defining the nature of the loadings between the factors and variables. The six factors, namely (1) History, (2) Language, (3) Politics, (4) People, (5) Organisational Goals and Values and (6) Performance Proficiency, were specified as each being measured by a specific subset of variables.
Maximum likelihood estimation (MLE) was used to estimate the coefficients. MLE is by far the most common model-fitting procedure used as it picks estimates that have the greatest chance of reproducing the observed data and does not depend on the scale of measurement (Garson, 2005). A limitation of MLE, however, is that it is sensitive to deviations from normality (DeCoster, 1998).

The model adequacy was then evaluated by means of goodnessof-fit measures. The model chi-square was used as it is the most common goodness-of-fit test. With the chi-square, the difference between the observed data and the hypothesised model is tested (Garson, 2005). In order for the postulated model to fit the data, the difference between the two should be minimal. Hence the chi-square should be non-significant if there is a good model fit while a significant chi-square indicates lack of satisfactory model fit (Garson, 2005). A limitation of the chi-square test is that the size of the sample has an impact on chi-square values. If the sample size is too small, the error terms will be large, which makes it difficult to detect a difference between the model and the data (Hox \& Bechger, 1998). Conversely, if the sample is too large, even small differences between the model and the data will result in a statistical significance. Hence with large samples the chi-square will almost certainly be significant.

Given the sensitivity of the chi-square statistic for sample size, a variety of alternative fit indices have been proposed by researchers. All goodness-of-fit measures are some function of the chi-square and degrees of freedom. These alternative indices consider not only the fit of the model but also its simplicity. Even though the goodness-of-fit indices still depend on sample size and distribution, the dependency is much smaller than that of the routine chi-square test (Hox \& Bechger, 1998). The EQS program prints 10 different goodness-of-fit indices, of which the following were used to determine goodness of fit in this study: the chi-square statistic, the non-normed fit index (NNFI), the comparative fit index (CFI), the incremental fit index (IFI), the goodness of fit index (GFI), the root mean squared error of approximation (RMSEA) and the model chi-square (Bentler \& Bonnet, 1980; Bentler, 1990).

A general guideline for the interpretation of the NNFI, CFI and GFI is that values of 0.90 indicate a satisfactory fit between the theoretical model and the observed data. A value of 0.95 and higher indicates a good model fit. The RMSEA takes into consideration the complexity of a theoretical model and generally gives preference to simpler models that use fewer parameters to explain the covariances between the variables (De Bruin \& Bernard-Phera, 2002). The general guideline is that values of 0.05 and smaller indicate a close fit between the theoretical model and observed data. Values of 0.08 and smaller indicate a reasonable fit, and values greater than 0.08 or equal to 1 indicate a poor fit and that the model clearly needs work.

\section{RESULTS}

The findings of the study are reported in terms of the descriptive statistics, the reliability analysis and the CFA, including the EQS model and goodness-of-fit indices. 
TABLE 3

Descriptive statistics for the socialisation instrument

\begin{tabular}{|c|c|c|c|c|c|}
\hline & & Mean & Std. Deviation & Skewness & Kurtosis \\
\hline \multicolumn{6}{|c|}{ QUEST. NO } \\
\hline 7 & Learnt how things really work & 3.882 & 0.768 & -0.748 & 0.668 \\
\hline $8 \mathrm{R}$ & Know very little about history of work group & 3.229 & 1.083 & -0.186 & -1.071 \\
\hline 9 & Good representative of organisation & 4.288 & 0.725 & -0.784 & 0.295 \\
\hline $10 \mathrm{R}$ & Co-workers not my friends & 3.765 & 1.178 & -0.872 & -0.071 \\
\hline $11 \mathrm{R}$ & Have not learnt the ropes of my job & 3.812 & 1.077 & -0.739 & -0.282 \\
\hline $12 \mathrm{R}$ & Have not mastered specific terminology and vocabulary & 3.371 & 1.145 & -0.168 & -1.038 \\
\hline 13 & Know who influential people are & 3.729 & 0.902 & -0.954 & 1.148 \\
\hline 14 & Learnt to perform job successfully & 4.100 & 0.908 & -1.160 & 1.265 \\
\hline $15 \mathrm{R}$ & Not familiar with customs, rituals, etc. & 3.241 & 1.179 & -0.283 & -0.972 \\
\hline $16 \mathrm{R}$ & Excluded in social get-togethers & 3.753 & 0.966 & -0.802 & 0.515 \\
\hline 17 & Goals of the organisation are my goals & 4.153 & 0.857 & -0.986 & 0.564 \\
\hline $18 \mathrm{R}$ & Have not mastered the slang and jargon & 3.318 & 1.068 & -0.104 & -0.858 \\
\hline 19 & In work group I'm seen as "one of the gang" & 3.312 & 1.078 & -0.535 & -0.566 \\
\hline 20 & Know organisation's long-held traditions & 3.194 & 0.931 & -0.264 & -0.583 \\
\hline $21 R$ & Do not always understand abbreviations and acronyms & 3.076 & 1.131 & 0.122 & -1.176 \\
\hline 22 & Believe I fit in well with the organisation & 4.141 & 0.724 & -0.694 & 1.187 \\
\hline $23 R$ & Do not always believe in the values set by the organisation & 3.518 & 1.045 & -0.441 & -0.526 \\
\hline 24 & Understand specific meanings of words and jargon & 3.535 & 0.885 & -0.342 & -0.410 \\
\hline 25 & Have mastered the required tasks of my job & 3.724 & 0.973 & -0.667 & -0.037 \\
\hline 26 & Understand the goals of organisation & 4.241 & 0.561 & 0.006 & -0.341 \\
\hline 27 & Good resources describing background of work group & 3.735 & 0.853 & -0.444 & -0.030 \\
\hline $28 \mathrm{R}$ & Have not fully developed appropriate skills and abilities & 3.141 & 1.284 & -0.081 & -1.239 \\
\hline $29 \mathrm{R}$ & Do not have a good understanding of the politics in the organisation & 2.918 & 1.046 & 0.103 & -0.630 \\
\hline 30 & Understand what the duties of job entail & 4.053 & 0.809 & -0.776 & 0.439 \\
\hline 31 & Good example of employee who represent organisation goals & 4.041 & 0.787 & -0.589 & 0.074 \\
\hline $32 \mathrm{R}$ & Not always sure to get desirable work assignments & 3.371 & 1.031 & -0.270 & -0.683 \\
\hline $33 R$ & Usually excluded in informal networks / gatherings & 3.571 & 0.984 & -0.520 & -0.242 \\
\hline 34 & Have a good understanding of the motives of others & 3.371 & 0.896 & -0.453 & 0.074 \\
\hline 35 & I'm familiar with the history of the organisation & 3.447 & 0.904 & -0.424 & -0.212 \\
\hline 36 & Understand most of the acronyms and abbreviations & 3.494 & 0.899 & -0.601 & -0.085 \\
\hline 37 & I'm pretty popular in the organisation & 3.135 & 0.935 & -0.142 & -0.450 \\
\hline 38 & Can identify those most important in getting work done & 3.876 & 0.747 & -0.569 & 0.418 \\
\hline 39 & Believe most of my co-workers like me & 3.604 & 0.825 & -0.047 & -0.209 \\
\hline 40 & I support the goals set by my organisation & 4.254 & 0.682 & -0.597 & 0.200 \\
\hline
\end{tabular}

The descriptive statistics for the socialisation instrument are set out in Table 3. The variability of the mean, standard deviation, skewness and kurtosis reflects how the participants responded to the different items of the questionnaire. An analysis was conducted on the data set as it appears in the instrument as well as on the data set when the negatively stated statements were reversed. The analysis of the data set reflecting the responses to the reversed negatively stated items is depicted in Table 3 . The only difference observed between the two sets is that the mean values differ. The reversed items do not influence the standard deviation, skewness and kurtosis values. The variability indicates that the data collected and analysed were normally distributed. Skewness values are less than one, indicating that the distribution does not differ significantly from a normal distribution.

The results of the reliability analysis are set out in Table 4 . The alpha coefficients for the six constructs are the following: 0.677 (History), 0.797 (Language), 0.541 (Politics), 0.688 (People), 0.767 (Organisational Goals and Values) and 0.731 (Performance
Proficiency). It appears that the construct Politics had the lowest and least acceptable coefficient while the rest were in line with the guideline (Chao et al., 1994; Klein \& Weaver, 2000). According to Kline (1986) items should ideally correlate beyond 0,2 with the total score. In this case, all items correlate above 0,2 except item 32R. All items appear to contribute positively to scale reliability except for items $32 R, 19,23 R$ and $11 R$ that impact negatively on the reliability of the particular scale.

The Kaiser-Meyer-Olkin (KMO) measure and the Bartlett test of sphericity were used to determine sampling adequacy (Kim \& Mueller, 1978). The KMO guideline is that values close to 1 indicate that factor analysis will be useful with the data. Values less than 0.5 indicate that factor analysis will not be useful. The Bartlett guideline is that values less than 0.05 indicate that there are probably significant relationships among the variables. Values higher than 0.10 indicate that the data are not suitable for factor analysis. The KMO measure of sampling adequacy was 0.850 . The Bartlett test of sphericity was significant (chi-square $=2,225.57, d f=561$ and $P<0.000$ ). Both these measures indicated that the data were appropriate for factor analysis. 
TABLE 4

Reliability analysis

\begin{tabular}{llrr}
\hline Factor & Question No & $\begin{array}{c}\text { Corrected Item } \\
\text { - Total Correlation }\end{array}$ & $\begin{array}{r}\text { Alpha if item is } \\
\text { deleted }\end{array}$ \\
\hline HISTORY & & & \\
\hline & Q8R & 0.4064 & 0.6389 \\
& Q15R & 0.3424 & 0.6770 \\
Q20 & 0.5379 & 0.5811 \\
& Q27 & 0.3206 & 0.6691 \\
& Q35 & 0.5993 & 0.5568 \\
& &
\end{tabular}

LANGUAGE

$\begin{array}{lrl}\text { Q12R } & 0.5383 & 0.7747 \\ \text { Q18R } & 0.5847 & 0.7570 \\ \text { Q21R } & 0.5861 & 0.7576 \\ \text { Q24 } & 0.6098 & 0.7531 \\ \text { Q36 } & 0.6066 & 0.7534 \\ & \text { Scale reliability }=0.7974 & \end{array}$

POLITICS

$\begin{array}{lrr}\text { Q7 } & 0.3199 & 0.4830 \\ \text { Q13 } & 0.2710 & 0.5015 \\ \text { Q29R } & 0.3341 & 0.4695 \\ \text { Q32R } & 0.1767 & 0.5542 \\ \text { Q34 } & 0.2723 & 0.5009 \\ \text { Q38 } & 0.3852 & 0.4579 \\ & \text { Scale reliability }=0.5405 & \end{array}$

PEOPLE

$\begin{array}{lrl}\text { Q10R } & 0.4323 & 0.6454 \\ \text { Q16R } & 0.5531 & 0.6035 \\ \text { Q19 } & 0.2284 & 0.7128 \\ \text { Q33R } & 0.4992 & 0.6207 \\ \text { Q37 } & 0.4044 & 0.6523 \\ \text { Q39 } & 0.4440 & 0.6436 \\ & \text { Scale reliability }= & 0.6883\end{array}$

ORGANISATIONAL GOALS AND VALUES

\begin{tabular}{|c|c|c|}
\hline Q9 & 0.4666 & 0.7425 \\
\hline Q17 & 0.5374 & 0.7272 \\
\hline Q22 & 0.5004 & 0.7360 \\
\hline Q23R & 0.2127 & 0.8171 \\
\hline Q26 & 0.5850 & 0.7285 \\
\hline Q31 & 0.6553 & 0.7016 \\
\hline Q40 & 0.6532 & 0.7083 \\
\hline & Scale reliability $=0.7670$ & \\
\hline PERFORMANCE PROFIC & & \\
\hline Q11R & 0.3333 & 0.7468 \\
\hline Q14 & 0.5196 & 0.6769 \\
\hline Q25 & 0.6459 & 0.6263 \\
\hline Q28R & 0.5133 & 0.6853 \\
\hline Q30 & 0.5211 & 0.6817 \\
\hline & Scale reliability $=0.7310$ & \\
\hline
\end{tabular}

A CFA was then performed on the total sample to determine whether the postulated theoretical model fitted the observed data. As is indicated in Table 5, the NNFI, CFI, IFI and GFI values were $0.780,0.800,0.805$ and 0.756 respectively. A value of 0.90 is considered to be a good fit for all of the above indices (Bentler, 1990; Bentler \& Bonnet, 1980). None of these values met the guideline to be acceptable. The RMSEA had a value of 0.065 . The guideline is that it should be at or below 0.05 for a well-fitting model and at or below 0.08 for a reasonably fitting model. This indicates that the RMSEA value deems the model a reasonable fit. The chi-square was 880.579 , with $512 \mathrm{df}(P<$ $0.000)$ for the sample. Hence the chi-square is non-significant. A non-significant chi-square value depicts a good model fit (Garson, 2005). The chi-square/df ratio was 1.72. Carmines and
TABLE 5

Fit indices for the postulated measuring model $(\mathrm{N}=170)$

\begin{tabular}{lr}
\hline Model & \multicolumn{2}{c}{ Value } \\
\hline Chi-square & 880.579 \\
(df) & 512 \\
P & 0.000 \\
NNFI & 0.780 \\
CFI & 0.800 \\
IFI & 0.805 \\
GFI & 0.756 \\
RMSEA & 0.065 \\
\hline
\end{tabular}

McIver (1981) claim that the relative chi-square should be in the 2:1 to 3:1 range for an acceptable model. Thus the chi-square of 1.72 can be interpreted as indicating a good fit.

The structural equation model for the six factors underlying the socialisation instrument is given in Figure 1. The latent variables or factors have been allowed to correlate with one another, as is depicted by the curved arrows between them. The path coefficients show high correlations between some of the constructs: History and Politics (1.031); Language and Politics (1.009); Performance Proficiency and Politics (0.966); Language and Performance Proficiency (0.907); and History and Language (0.864). From this it appears that of the six constructs, Politics has a strong correlation with many of the other constructs. The observed variables load on one factor only. Hence the arrows depict path coefficients from these observed variables to only one latent variable or factor respectively. The path coefficients for the factor History vary between 0.459 and 0.707 . For Language, the coefficients vary from 0.593 to 0.748 . The Politics coefficients vary from 0.308 to 0.529 . The coefficients for the factor People vary from 0.239 to 0.732 . For Organisational Goals and Values the coefficients vary between 0.220 and 0.771 . Finally, the coefficients for Performance Proficiency vary between 0.377 and 0.785 . In addition, certain of the items yielded very low coefficients: variable $34(0.308)$, variable $19(0.239)$ and variable $23(0.220)$.

\section{DISCUSSION}

Construct validity refers to the degree to which an instrument measures what it purports to be measuring. To determine the construct validity of the socialisation instrument, the analysis focused on evaluating the instrument for measuring organisational socialisation.

The analysis set out to show how CFA could be used to assess the validity of the data obtained with the socialisation instrument by testing the relationships among the items or observed variables that comprise each of the six constructs of organisational socialisation. The data obtained were analysed in terms of (1) the reliability of the instrument and (2) confirmation of the observed variables deemed to measure each of the six constructs respectively.

According to the reliability analysis results five of the six constructs' reliability is acceptable, with estimates ranging from 0.687 to 0.797 . The construct Politics yielded the lowest reliability (0.541). It is also important to note that previous research has not yielded low reliability results for this construct (Chao et al., 1994; Klein \& Weaver, 2000). The reliability results correlate with previous research conducted with this instrument, confirming the instrument to be reliable. These results are important to construct validation since an instrument cannot be deemed valid if it is not reliable. Any threat to an instrument's reliability poses a threat to its construct validity (Brown, 2000). 


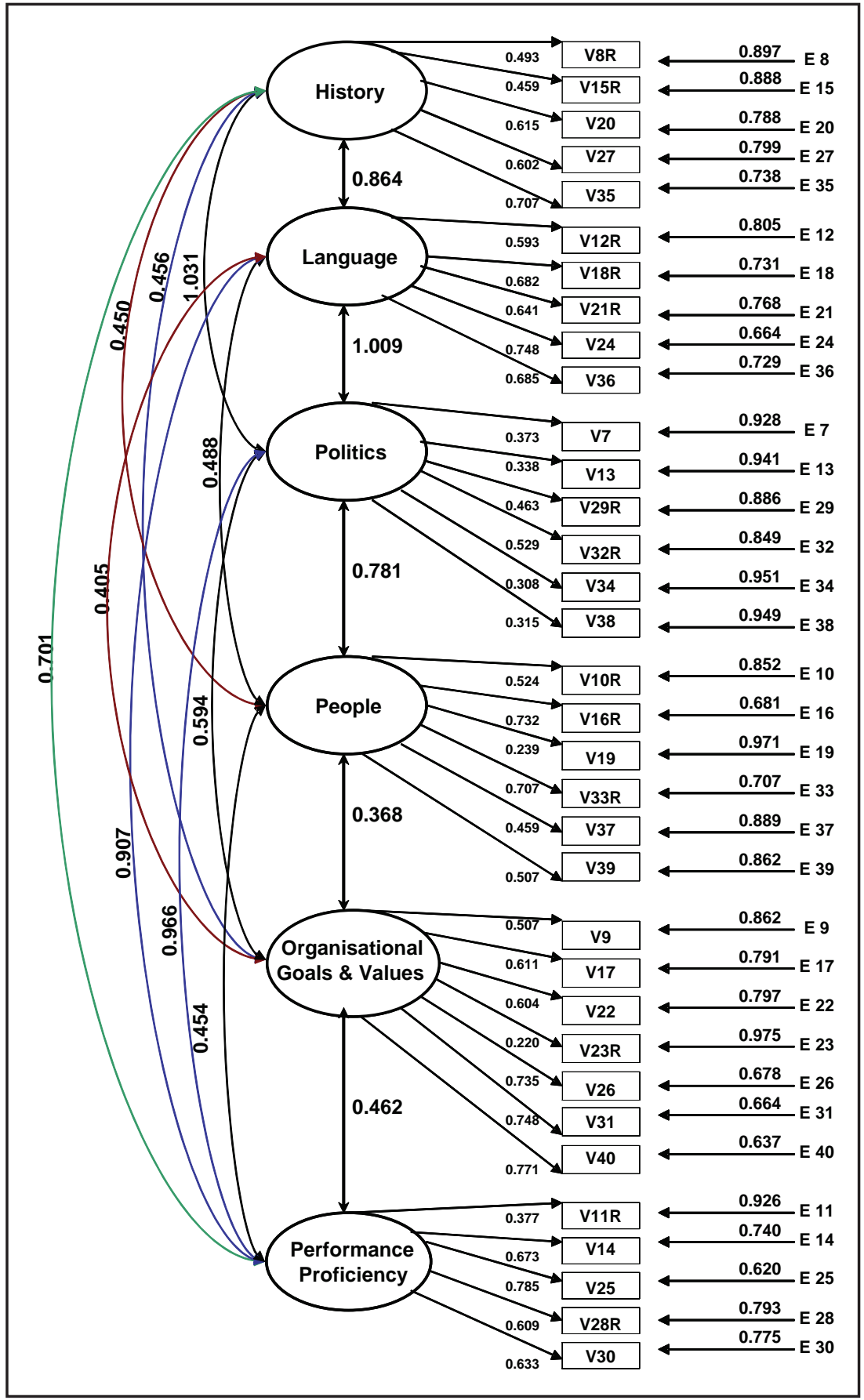

FIGURE 1

Structural equation model

CFA offered further and more specific insight into the factor structure of the socialisation instrument by providing tests of significance of each factor loading. As far as CFA is concerned, even though the goodness-of-fit indices (NNFI, CFI, IFI and GFI) do not indicate an acceptable fit of the postulated model to the data obtained, the RMSEA indicates a reasonable fit, and the chi-square indicates a good fit. Hence it can be deduced that the construct validity of the instrument, based on CFA, is acceptable.

Chao et al. (1994) evaluated the dimensionality of this instrument based on the theory that organisational socialisation is multidimensional. This implies that the constructs of the instrument should be relatively independent so that socialisation in one area is not necessarily related to socialisation in another (Chao et al., 1994).
In the CFA, the construct Politics correlated strongly with the constructs History, Language and Performance Proficiency. It was also found that the path coefficients for this construct were very low in comparison to those for the other constructs. These findings raise questions about whether the construct of organisational socialisation is simply measured poorly by the instrument or whether it forms part of the other constructs that it correlated strongly with.

\section{Limitations and recommendations}

Some limitations and recommendations must be borne in mind concerning the findings of this study:

- The demographic profile of the sample warrants caution in generalising the results to the larger population. Given the current reality of South Africa regarding employment 
equity, the appointment of more black, Asian and coloured recruits who are mostly in the age range of 20 to 30 years of age, mainly in clerical positions, has influenced the sample. Fewer white recruits and fewer incumbents of specialist, managerial and supervisory positions are evident in the sample. Hence the sample was not adequate in terms of heterogeneity. It might have yielded different results if it had been more heterogeneous.

- The sample size $(\mathrm{N}=170)$ was sufficient to analyse the instrument, but it would have been necessary for it to be bigger and more representative of different cultural groups if this study had wanted to make meaningful cross-cultural comparisons.

- From a survey research perspective, the researcher was not present when the respondents completed the questionnaires. Hence respondents were not able to request clarification of the questions by the researcher, and this could have had an impact on the results.

- Obtaining a 'good-fitting' model when conducting structural equation modelling, as in CFA, does not confirm that the resulting model is the only acceptable or correct model. It merely confirms that the theoretical model underpinning the instrument is consistent with the observed data. Future research could result in revised theoretical models of organisational socialisation that differ.

- It is recommended that future research conduct an EFA with data obtained from a larger, more heterogeneous sample. EFA will provide the opportunity to explore the empirical data for characteristic features without imposing a definite model on the data. This could be followed by CFA, which would be useful in comparing groups based on race, gender, age, and so on.

- Future validation studies could focus on improving the model fit of the theoretical model underpinning this measure of organisational socialisation. It would also be useful to review the theory underpinning this instrument by postulating more than one model and determining its fit to the data observed in order to obtain a better model fit.

- It is recommended that the items of the instrument that yielded low reliability be taken out to determine the influence thereof on the resulting findings of future validation studies.

\section{Conclusion}

The significance of the findings of this study is that, from a South African perspective, the socialisation instrument can be useful in measuring organisational socialisation. This instrument can also be valuable in assessing the effectiveness of the socialisation tactics used by organisations.

The socialisation instrument, as a valid and reliable measurement of organisational socialisation, could expand the understanding of this dimension of the employer-employee relationship. With further refinement, it could provide valuable information about what newcomers learn in the process of organisational socialisation and what should be focused on in this process.

According to Czakan, the managing director of Kelly, a new employee must be able to integrate seamlessly into the workforce. How a new employee fits into an organisation has a significant effect on the continued success of the team and the business as a whole. Organisations are not simply filling a space but are adding a new member to the organisation. Organisations need employees who fit in with the organisation, with the work group within which they will operate and with the requirements of the job. If the right fit is not achieved, this can have an impact on the work group and on the business as a whole. However, research on organisational socialisation within a South African context is limited and further research is warranted.

\section{REFERENCES}

Bauer, T.N. \& Green, S.G. (1994). Effect of newcomer involvement in work-related activities: a longitudinal study of socialization. Journal of Applied Psychology, 79(2), 211-223.

Bentler, P.M. \& Bonnet, D.G. (1980). Significance tests and goodness-of-fit in the analysis of covariance structures. Psychological Bulletin, 88, 588-606.

Bentler, P.M. (1990). Comparative fit indexes in structural models. Psychological Bulletin, 107, 238-246.

Brown, J.D. (2000). Statistics corner questions and answers about language testing statistics: what is construct validity? Shiken: JALT Testing E Evaluation SIG Newsletter, 4(2), 7-10. Retrieved 11 October 2005 from http://www.jalt.org/test/ bro_8.html

Carmines, E.G. \& McIver, J.P. (1981). Analyzing models with unobserved variables: analysis of covariance structures. Thousand Oaks, CA: Sage.

Chao, G.T, O'Leary-Kelley, A.M., Wolf, S., Klein, H.J. \& Gardner, P.D. (1994). Organizational socialization: its content and consequences. Journal of Applied Psychology, 79(5), 730-743.

Chatman, J.A. (1991). Matching people and organizations: selection and socialization in public accounting firms. Administrative Science Quarterly, 36(1), 459-485.

Chow, I.H. (2002). Organizational socialization and career success of Asian managers. International Journal of Human Resources Management, 13(4), 720-737.

De Bruin, G.P. \& Bernard-Phera, M.J. (2002). Confirmatory factor analysis of the Career Development Questionnaire and the Career Decision-making Self-efficacy Scale for South African High School Students. SA Journal of Industrial Psychology, 28(2), 1-6.

DeCoster, J. (1998). Overview of factor analysis. Retrieved 16 September 2005 from http://www.stat-help.com/notes. html

Dessler, G. (1984). Personnel management: modern concepts and techniques. Reston, VA: Reston Publishing.

Feldman, D.C. (1976). A contingency theory of socialization. Administrative Science Quarterly, 21, 433-451.

Feldman,D.C. (1981). Themultiple socialization of organizational members. Academy of Management Review, 6(2), 309-318.

Garson, G.D. (2005). Statsnotes: an online textbook, PA 765. Retrieved 16 September 2005 from http://www2.chass. ncsu.edu/garson/pa765/statnote.html

Gomersall, E.R. \& Myers, M.S. (1966). Breakthrough in on-thejob training. Harvard Business Review, 44(4), 62-72.

Griffin, A.E.C., Colella, A. \& Goparaju, S. (2000). Newcomer and organizational socialization tactics: an interactionist perspective. Human Resource Management Review, 10(4), 453-474.

Harvey, R.J., Billings, R.S. \& Nilan, K.J. (1985). Confirmatory factoral analysis of the Job Diagnostic Survey: good news and bad news. Journal of Applied Psychology, 70(3), 461-468.

Hox, J.J. \& Bechger, T.M. (1998). An introduction to structural equation modelling. Family Science Review, 11, 354-373.

Ivancevich, J.M. \& Matteson, M.T. (1990). Organizational behaviour and management. Homewood, IL: Irwin.

Jones, G.R. (1983). Psychological orientation and the process of organizational socialization: an interactionist perspective. Academy of Management Review, 8(3), 464-474.

Jones, G.R. (1986). Socialization tactics, self-efficacy and newcomers' adjustments to organizations. Academy of Management Journal, 29(2), 262-279.

Kim, J. \& Mueller, C.W. (1978). Factor analysis: statistical methods and practical issues. Sage University Paper series on Quantitative Applications in the Social Sciences, series no 07-014. Beverley Hills, CA: Sage.

Klein, H.J. \& Weaver, N.A. (2000). The effectiveness of an organizational-level orientation training programme in the socialization of new hires. Personnel Psychology, 53, 47-66.

Kline, R.B. (1986). Principles and practice of structural equation modelling. New York: Guilford. 
Lewis, P.S., Goodman, S.H. \& Fandt, P.M. (1998). Management: challenges in the $21^{\text {st }}$ century. Cincinnati, Ohio: South-Western College Publishing.

Louis, M.R. (1980). Surprise and sense making: what newcomers experience in entering unfamiliar organizational settings. Administrative Science Quarterly, 25, 226-251.

Manning, P.K. (1977). Talking and becoming: a view of organizational socialization. In R.L. Blankenship (Ed.), Colleagues in organization: the social construction of professional work. London: Wiley \& Sons.

Morrison, E.W. (2002). Newcomers' relationships: the role of social network ties during socialization. Academy of Management Journal, 45(6), 1149-1160.

Nel, P.S., Gerber, P.D., Van Dyk, P.S., Haasbroek, G.D., Schultz, H.B., Sono, T. \& Werner, A. (2001). Human resources management. Cape Town: Oxford.

Newstrom, J. W. \& Davis, K. (1993). Organizational behavior, human behavior at work. Boston, MA: McGraw-Hill.

Ostroff, C. \& Kozlowski, S.W.J. (1992). Organisational socialisation as a learning process: the role of information acquisition. Personnel Psychology, 45, 849-874.

Pfeffer, J. (1981). Power in organizations. Marshfield, MA: Pitman.

Porter, L.W., Lawler, E.E. III \& Hackman, J.R. (1975). Behavior in organizations. New York: McGraw-Hill.
Reichers, A.E. (1987). An interactionist perspective on newcomer socialization rates. Academy of Management Review, 12(2), 278-287.

Ritti, R.R. (1994). The ropes to skip and the ropes to know. New York: Wiley.

Robbins, S.P. (1998). Organizational behaviour. Upper Saddle River, NJ: Prentice Hall.

Schein, E.H. (1968). Organizational socialization and the profession of management. Industrial Management Review, 9, 1-16.

Schein, E.H. (1992). Organizational culture and leadership. San Francisco: Jossey-Bass.

Schneider, B. \& Reichers, A.E. (1983). On the etiology of climates. Personnel Psychology, 36, 19-39.

Schneider, B. (1987). The people make the place. Personnel Psychology, 40, 437-453.

Storm, L \& Roodt, G. (2002). Die verband tussen organisasiesosialisering en organisasieverbondenheid. SA Journal of Industrial Psychology, 28(1), 14-21.

Wanous, J.P., Reichers, A.E. \& Malik, S.D. (1984). Organizational socialization and group development: toward an integrative perspective. Academy of Management Review, 9(4), 670-683. 